\title{
Prevalence and Distribution of Soil Transmitted Helminths (STH) among Asymptomatic School Going Children in South Chennai, Tamil Nadu, India.
}

\author{
Anbumani. N., Mallika M. \\ Associate Professor, Department of Microbiology, Sri Ramachandra University, Porur, Chennai-600116. Department of Microbiology, \\ Sri Ramachandra University, Porur, Chennai-600116.
}

\section{A B STRACT}

Soil transmitted helminth (STH) infections represent a major health problem in poor and developing countries. We conducted a pilot study to determine the prevalence of STH among school going children of Kancheepuram district. Three hundred and fifty eight children in the age group of 5-10 years were examined for STH. One hundred and fourteen of the $358(40 \%)$ were tested positive for various intestinal helminths. The various intestinal helminths are Ascaris lumbricoides, Trichuris trichiura and Taenia species. At least one intestinal helminth was detected in $25.13 \%$ (90/358) children and multiple helminth infestation was recorded in $15.08 \%$ (54/358). The most common parasitic helminth was A. lumbricoides $60 \%$ (84/144) followed by T. trichiura $4.17 \%$ (6/144). A. lumbricoides was found as single type infection as well as in association with other helminths in mixed type infection. This study emphasizes the need for improved sanitation and better living conditions for the school-age children in rural areas.

Key words:

\section{INTRODUCTION}

Soil-transmitted helminths (STH) are one of the most important groups of infectious agents and are causing world's major human health problems until now. The commonest parasitic infections reported globally are Ascaris $(20 \%)$, hookworm (18\%), Trichuris trichiura $(10 \%)$ and Entamoeba histolytica $(10 \%)$. It is estimated that as much as $60 \%$ of the world's population is infected with gut parasites, which may play a role in morbidity due to intestinal infestations. Inadequate hygiene, poor health care systems and facilities, social indifference, social instability, civil war and natural disasters make situations worse. ${ }^{1}$ STH are more important among children and in poor or malnourished populations. It has been shown to contribute to anaemia, stunted growth, and underweight and poor school performance. ${ }^{2}$ The prevalence and distribution of soil transmitted helminthes (STH) among asymptomatic school going children in Tambaram, Kancheepuram district of South Chennai, Tamilnadu, has not been studied till now.

\section{Address for correspondence:}

E-mail:dranbumani@yahoo.co.in

DOI: 10.5530/ijmedph.2.2011.14
We hence conducted a pilot study to determine the prevalence of helminthes infestations among school going children of Kancheepuram district.

\section{MATERIALS AND METHODS}

This study was conducted in a middle School located in the rural areas of Tambaram, Kancheepuram District during January 2008. Stool samples were collected from 358 children, which included $179(50 \%)$ males and $179(50 \%)$ females in the age group of 5 to 10 years. The importance of the study was explained to all the children in the study population and the methods of collecting stool specimens were thoroughly made clear to all the children. They were provided with labelled, clean stool containers with a proper lid. Every child was instructed to bring his/her own stool sample so that no mixing would occur. After collection, the specimens were immediately transported to Microbiology laboratory for further processing. A total of 358 stool samples were examined by routine microscopy using normal saline and Lugol's Iodine preparation as well as by Saturated Sodium Chloride floatation technique. All the parasitic eggs or worms recovered were recorded and descriptively analysed. A difference in the prevalence of parasitic infection and difference with respect to age and gender was compared by using $\chi^{2}$ (Chi-square) test. 


\section{RESULTS}

Three hundred and fifty eight children between age of 5 to 10 years, both male [ $n=179]$ and female [ $n=179]$ were included in this study. The overall prevalence of helminthic parasitic infection was 40\% [144/358].

At least one intestinal helminth was detected in 25.13\% (90/358) children and multiple helminth infestation was recorded in $15.08 \%$ (54/358). The most common parasitic helminth was Ascaris lumbricoides 60\% (84/144) followed by Trichuris trichiura $4.17 \%$ (6/144). A. lumbricoides was found as single type infection as well as in association with other helminths in mixed type infection. Mixed type infection includes A. lumbricoides + T.trichiura 25\% (36/144), A. lumbricoides + Taenia species $6 \%(8 / 144)$, and A. lumbricoides + T. trichiura + Taenia species 7\% (10/144) (Table.1).

Age and gender wise prevalence of various types of helminths in the children were shown in Table 2 and 3. In this study, the rate of infestation was comparatively higher among the boys $(66.67 \%)$ than in girls $(33.33 \%)$. A $p$ value of $>0.206\left[\chi^{2}=3.16\right]$ reveals no statistically significant difference in the prevalence of A. lumbricoides, T. trichiura, Taenia species between boy and girl children.

\begin{tabular}{lc} 
Table 1: Title missing \\
\hline At least One helminth parasite & $25.13 \%(90 / 358)$ \\
Multiple helminth Infection & $15.08 \%(54 / 358)$ \\
Ascaris lumbricoides & $60 \%(84 / 144)$ \\
Trichuris trichiura & $4.17 \%(6 / 144)$ \\
Ascaris lumbricoides + Trichuris trichiura & $25 \%(36 / 144)$ \\
Ascaris lumbricoides + Taenia species & $6 \%(8 / 144)$ \\
Ascaris lumbricoides + Trichuris trichiura + & $7 \%(10 / 144)$ \\
Taenia species & \\
\hline
\end{tabular}

\begin{tabular}{|c|c|c|c|}
\hline $\begin{array}{l}\text { Parasitic } \\
\text { Infection }\end{array}$ & $\begin{array}{c}\text { Males } \\
(n=179)\end{array}$ & $\begin{array}{l}\text { Female } \\
(n=179)\end{array}$ & Total \\
\hline $\begin{array}{l}\text { Ascaris } \\
\text { lumbricoides }\end{array}$ & $64.02 \%(89)$ & $35.97 \%(50)$ & $38.82 \%(139)$ \\
\hline $\begin{array}{l}\text { Trichuris } \\
\text { trichiura }\end{array}$ & $50 \%(25)$ & $50 \%(25)$ & $13.96 \%(50)$ \\
\hline $\begin{array}{l}\text { Taenia } \\
\text { species }\end{array}$ & $64.70 \%(11)$ & $35.29 \%(6)$ & $4.74 \%(17)$ \\
\hline
\end{tabular}

Age - wise infestation rate was $21 \%, 15 \%$ and $5 \%$ in the 9 to 10,7 to 8 and 5-6 year age group respectively. There is no statistically significant difference with respect to age. $(P>0.92)\left[\chi^{2}=0.16\right]$.

\section{DISCUSSION}

The present study investigated the prevalence and distribution of soil-transmitted helminths among the asymptomatic school going children. The prevalence rate of soil transmitted helminths was $40 \%$ (144/358). In India, the overall prevalence rates ranges from $13-66 \%$ with varying prevalence rates for individual parasites. ${ }^{3}$ Similar reports have been seen in several developing countries like Malaysia, Nepal, Kuwait, and several parts of Kenya, Guyana and South Africa.(2).

The most prevalent soil - transmitted helminth was A. lumbricoides in all age groups in agreement with Saldira et al. 1999, and Carla scolari et al.,5 The prevalence of $A$. lumbricoides and T. trichiura was higher in the mid school then in the primary school. It was found in the study that $25.13 \%$ (90/358) were infected by at least one helminthic parasite and $15.08 \%(54 / 358)$ were infected by multiple helminthic parasites. Lindo et al. in young children in the interior of Guyana and Legesse et al. found in the lake Langano, Ethiopia, have shown similar results in their studies. ${ }^{6,7}$

The results of this study indicate that $A$. lumbricodies was the commonest helminthic parasite in both male $(75 \%)$ and female $(61 \%)$ children, followed by T. trichura, $26.2 \%$ in male and $36.3 \%$ in female children. This may be due to the presence of the source of the infection in the area studied and frequent faeco - oral spread of infection among children. In addition, contamination of soil by human faeces (especially for Ascaris and Trichuris) in combination with a high degree of overcrowding and a low-income level increases the susceptibility to helminthiasis. Similar results were shown by Lindo et al. ${ }^{6}$ and $\mathrm{Al}-\mathrm{Nakkas}$ et al. ${ }^{8}$ in Kuwait.

Data analysis reveals a higher percentage in males (54\%) than females $(27 \%)$ which is statistically not significant $(p$ value $>0.92)$. This is due to the fact that males and females are more exposed to unhygienic conditions in field

\begin{tabular}{|c|c|c|c|c|c|c|c|}
\hline \multirow[t]{2}{*}{ Age Group } & \multicolumn{3}{|c|}{ Males } & \multicolumn{3}{|c|}{ Females } & \multirow[t]{2}{*}{ Overall +ve\% } \\
\hline & No Screened & +ve & $\%$ & No Screened & +ve & $\%$ & \\
\hline $5-6$ & 26 & 12 & 46.25 & 31 & 5 & 16.12 & $4.74 \%$ \\
\hline $7-8$ & 64 & 34 & 53.12 & 64 & 18 & 28.12 & $14.52 \%$ \\
\hline $9-10$ & 89 & 50 & 56.17 & 84 & 25 & 29.76 & $20.94 \%$ \\
\hline Overall & 179 & 96 & 53.63 & 179 & 48 & 26.81 & $40 \%$ \\
\hline
\end{tabular}


during playing. Similar results have been reported by Singh et al. in rural community of Varanasi and Ibrahim in 2002, among school children in Gaza strip, Palestine. ${ }^{9,10}$

Our data are consistent with a direct effect of the lack of sanitation on prevalence/intensity of intestinal helminth infections as suggested by others. ${ }^{5}$ Populations living close to each other may have different risks for STH infections if their social economic status and their living conditions differ. For an appropriate control strategy it is important to conduct epidemiological surveys which are able to detect these differences. However, the survey was basically aimed at providing the awareness of STH among school going children and need to improve the standards of living in rural setup which may decrease STH infections.

\section{CONCLUSION}

This study shows that intestinal helminths are prevalent in high magnitude among school children of the study area. This calls for the institution of control measures, including treatment of all school - age children, improvement of sanitation and provision of clean water. The impact of each measure would be maximized through a health education programme directed at school children in particular and at community in general.

\section{ACKNOWLEDGEMENT}

We would like to thank all the children, their parents, teachers and the school authorities for their co-operation. We also thank our Post graduates, Anandhi. L„Kavitha .A and Uma Maheshwari for helping us conduct the survey of the children

\section{REFERENCES}

1. Bundy \& deSilva DAP. Epidemiological aspects of Trichuris trichuriasis in Caribbean communities. Transaction of Royal Society of Tropical medicine and Hygiene.1998; 80:706-718.

2. World Health Organization, Prevention and Control of intestinal parasitic Infections. Report of a WHO Expert Committee. World Health Organ Tec Rep Ser/ 1987; 749.

3. Gagandeep kang, Marys, Mathew D, Parasanna Rajan, Jasper D. Daniel, Minnie M. Mathan, V.I. Mathan, J.P. Muliyil, Prevalence of intestinal parasites in Rural Southern Indian Tropical Medicine and International Health, 1998; 3(1):70-75.

4. Saldira SR, Silveria AS, Philippi ST et al. Ascaris - Trichuris association and malnutrition in Brazilian children. Paediatric and perinatal Epidemiology. 1999; 13, 89-98.

5. Carla Scolari, Carla Torti et al. Prevalence and distribution of soiltransmitted helminth (STH) infection in urban and indigenous school children in oritigueira, state of panama, Brazil; implications for control. Tropical medicine and International health, 2000; 5:302-307.

6. Lindo JF, Validum L, Ager AL, CampaA, Cuadrado RR, Intestinal parasites among young children in the interior of Guyana. West Indian Med J. 2002; 51:25-27.

7. Crompton DWT. How Much Human helminthiasis is there in the world? J. Parasitol, 1999; 85:397-403.

8. Legesse M, Erko B. Prevalence of intestinal parasites among school children in rural areas close to the South East of Lake Langano. Ethopia J Health Dev. 2004; 18:116-120.

9. Al-Nakkas EM, Al-Mutar MS, Sheweiki HS, Prem N, Shouky Rihan. Parasitic infection in Kuwait. A study based on primary care centres. Middle East J Fam Med. 2004; 3:118-124.

10. Singh DS, Hotchandani RK, Kumar S, Seecatt JS, Srivastava PK, Udupu $\mathrm{KN}$. Prevalence and pattern of intestinal parasitism. A rural community of Varanasi. Indian J Prev Soc Med. 1984; 15:1-8.

11. Ibrahim $\mathrm{AH}$. Prevalence of intestinal parasites among school children in Dier - El - Balah town in Gaza strip, Palestine. Ann Saudi Med. 2002; 22:273-275 